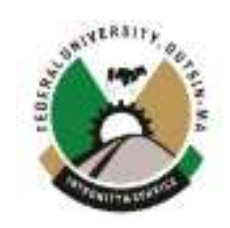

\title{
EVALUATION OF RESISTANCE IN TEN GENERATIONS OF CULEX QUINQUEFASCIATUS (SAY, 1823) EXPOSED TO METHANOLIC LEAF EXTRACT OF CALOTROPIS PROCERA
}

\author{
${ }^{1}$ Adamu, S. B., ${ }^{* 2}$ Sow, G. J. and ${ }^{2}$ Ndams, I. S. \\ ${ }^{1}$ Department of Biological Sciences, Aminu Saleh College of Education, Azare, Bauchi State \\ ${ }^{2}$ Department of Zoology, Ahmadu Bello University, Zaria \\ ${ }^{*}$ Corresponding author's email: charlygudzan@yahoo.co.uk
}

\begin{abstract}
Mosquitoes constitute a serious Public Health menace, resulting in millions of death worldwide each year. Emergence of insecticide resistant strains of the mosquitoes poses a serious threat and hence calls for alternative control measures. This study assessed the larvicidal efficacy of the methanolic leaf extract of Calotropis procera against the $3^{\text {rd }}$ instar larvae of Culex quinquefasciatus, after ten generations for 24 hours of exposure. Larvicidal activities of the leaf of the plant were studied on laboratory reared larvae of Culex quinquefasciatus at concentration ranges of $15 \mathrm{mg} / \mathrm{L}$ to $19 \mathrm{mg} / \mathrm{L}$. The LC50 values were obtained from Probit analysis at $95 \%$ confidence limit (CL). Results of the study indicated that the LC50 values obtained from the parent generation $\left(F_{0}\right)$ to the tenth generation $\left(F_{10}\right)$ were; $15.79 \mathrm{mg} / \mathrm{L}, 16.58 \mathrm{mg} / \mathrm{L}, 17.29 \mathrm{mg} / \mathrm{L}, 18.07 \mathrm{mg} / \mathrm{L}, 18.95 \mathrm{mg} / \mathrm{L}, 19.99$ $\mathrm{mg} / \mathrm{L}, 20.65 \mathrm{mg} / \mathrm{L}, 21.18 \mathrm{mg} / \mathrm{L}, 22.80 \mathrm{mg} / \mathrm{L}, 25.16 \mathrm{mg} / \mathrm{L}$ and $32.98 \mathrm{mg} / \mathrm{L}$ respectively at 24 hours. A higher efficacy of activity was exhibited by the extract at the parent generation $\left(\mathrm{F}_{0}\right)$ with lowest LC50 of $15.97 \mathrm{mg} / \mathrm{L}$ at $24 \mathrm{~h}$. The results of this research therefore underscore the efficacy of the plant and further suggest the use of the leaf extracts of Calotropis procera in the control of mosquito vectors and indirectly to the diseases they vectored.
\end{abstract}

Keywords: Calotropis procera, Culex quinquefasciatus, Generations, Lethal Concentration, Resistance ratio

\section{INTRODUCTION}

Culex quinquefasciatus Say is an important vector of a wide variety of pathogens and parasites of medical and veterinary diseases worldwide and is a potential vector of the filarial worm Wuchereria bancrofti, the agent of bancroftian filariasis (Jitpakdi et al., 1998; Triteeraprapab et al., 2000; Pumidonming et al., 2005). It also helps in transmitting malaria, dengue, chikungunya, filariasis Japanese encephalitis etc. which lead to thousands of deaths yearly [World Health Organization (WHO), 1995].

Culex quinquefasciatus is one of the most widespread mosquitoes in the world. It is found throughout most of pan and subtropical Americas (Andreadis et al., 2010), the Neotropics, Afrotropics (Diaz-Badillo et al., 2011), Indomalayan, Australian (David et al., 2012) and Eastern Asian regions of the world (Rios-Ibarra et al., 2010). It is also present in the United Kingdom and parts of the Middle East such as Pakistan, Iran among others. It is an important vector of periodic filariasis in parts of the world (Rios-Ibarra et al., 2010) and is known to transmit Wuchereria bancrofti to some degree in many regions of the globe. Of the estimated global 128 million lymphatic filarial cases, $91 \%$ are caused by Wuchereria bancrofti (Andreadis et al., 2010). Currently, the main tool for mosquito control is the use of diverse synthetic chemicals as larvicides and adulticides (Govindarajan and Rajeswary, 2014). The drastic effects of synthetic insecticides in the environment have received wide public apprehension (Morin and Comrie, 2010). Indeed, misuse of synthetic insecticides in agriculture and public health programmes has caused many problems like insecticide resistance, resurgence of pest species, environmental pollution, toxic hazards to humans and other non-target organisms (Sarwar et al., 2009). Chemical insecticides have the advantage of speedy action and easy application. However, their continuous use causes the development of resistance in insects in many parts of the world such as South America, Sudan, Sri Lanka, Nigeria, Burkina Faso, Egypt, Guatemala, USA, Turkey, and Syria (Malcolm, 1988; WHO, 1992). Consequently, several insecticides have been withdrawn. To overcome the problem of development of resistance in insects, attention is being given to natural products because of their biodegradable nature, nontoxic to other organisms, safer to use, easily available and cost effective, and have been used as alternative methods to control vectors of biological importance (WHO, 2002). A botanical phytochemical, with mosquitocidal potential are now recognized as potent alternative insecticides to replace synthetic insecticides in mosquito control programs due to their excellent larvicidal, ovicidal, adulticidal and repellent properties (Govindarajan et al., 2008). However, it is not known if these vectors will develop resistance to botanicals with continual usage. Therefore, this research aims at evaluating the resistance 
development on exposures of Culex quinquefasciatus larvae to methanolic extract of Calotropis procera. The result of this study may further strengthen the acceptance of using botanical as good substitute to synthetic insecticides.

Calotropis procera (Sodom apple), also called "babambi" in Fulfulde, belongs to the family Asclepiadaceae and is a soft wooded, evergreen perennial shrub. It is a xerophytic erect shrub, bearing purple spotted pink scented flowers (Shrivastava et al., 2013). The latex of C. procera is used as purgative, while the flower and dried leaves are considered as digestive aids, useful in cough, asthma and anorexia. The root bark is useful in treating skin diseases and intestinal worms; it also possesses analgesic, anticonvulsant, and sedative effect. It is highly recommended in the treatment of leprosy and hepatitis. Oil extracted from leaves of $C$. procera is very efficacious in treating cases of paralysis. Fresh leaves are utilized to relieve rheumatic pains and inflammation in joints (Verma et al., 2011). Calotropis procera possesses alkaloids, cardiac glycosides, anthraquinone, tannins, saponins, flavonoids, steroids, terpenoids, reducing sugars, and resins which are supposed to have significant antibacterial activity (Shaalan et al., 2005). The extracts of $C$. procera possess good larvicidal activity against mosquitoes and more studies shows that the extract contained more active compounds for future use against other stages in mosquito control (Shahia et al., 2010). The phytochemicals present in $C$. procera extracts has been found to act as antioxidants by scavenging free radicals and thus possessing therapeutic potentials (Patel et al., 2014).

\section{MATERIALS AND METHOD}

Collection and processing of plant materials: Fresh healthy leaves of Calotropis procera was collected from the botanical garden, Ahmadu Bello University, Zaria main Campus. Authentication of plant samples was done at the herbarium unit, Department of Botany, Ahmadu Bello University, Zaria and was assigned a Voucher no of 009219.

The leaves were thoroughly washed with tap water to avoid dusts and other unwanted materials accumulated on the leaves from their natural environment. The dust free leaves were then allowed to dry under shade at room temperature for about 20 days. The dried Calotropis procera was powdered by using mortar and pestle, sieved with a mesh size of $0.002 \mathrm{~mm}$ to collect fine powder.

Extraction and preparation of plant material: The dried $C$. procera leaves was pulverized and the material, thus obtained was cold macerated in organic solvent (methanol). Stock solution of the extract was prepared from $100 \mathrm{mg}$ of the solid residue dissolved in one litre (1L) of distilled water to obtain $100 \mathrm{mgL}^{-1}$ concentration. Serial dilution of this was made with distilled water to obtain test concentrations of $10 \mathrm{mgL}^{-1}, 20$ $\mathrm{mgL}^{-1}, 30 \mathrm{mgL}^{-1}$ and $40 \mathrm{mgL}^{-1}$. Control concentration, devoid of the plant extract, consisted of $99 \mathrm{ml}$ of distilled water and 1 ml methanol.

Collection and Rearing of Mosquitoes: Blood fed Female of Culex quinquefasciatus were collected from within Ahmadu Bello University, Zaria main campus using mechanical aspirators and brought to the laboratory. They were placed in entomological cage containing dechlorinated water for egg laying. The larval stages were fed with mouse pellet and the third instar larvae (L3) were exposed to various concentrations of methanolic leaf extract of Calotropis procera. The concentration that killed $50 \%$ of the larvae was determined. The survived larvae were reared to adult stage. A quail was introduced into the cage for the emerged female adult to have source of blood meal for about 6 hours, and allowed to lay eggs. The third instar larvae were exposed to determined LC50.This process was repeated until 10 generations were tested and resistance ratio was determined in each case.

Larval bioassay: Bioassay was performed according to WHO guidelines (2005). After making test concentrations, batches of 25 third instars larvae were transferred by means of droppers to small disposable test cups, each containing the test concentrations of $10,20,30$ and $40 \mathrm{mg} / \mathrm{L}$ while the control devoid of the extract contained $99 \mathrm{ml}$ of water and $1 \%$ methanol. Median Lethal Concentration $\left(\mathrm{LC}_{50}\right)$ of Leaves Extract: $\mathrm{LC}_{50}$ was determined as described by (Finney, 1971; Raymond, 1985) with little modification.

Resistance ratio (RR) in Culex quinquefasciatus: Resistance ratio (RR) was determined using the method of (Brown and Pal, 1971) as follows:

Resistance ratio $(\mathrm{RR})=$

\section{- $\mathrm{LC}_{50}$ of $\mathrm{F}_{0}$ generation $\mathrm{LC}_{50}$ of Tested generation}

Calculated RR values 10 are indicative of high resistance, 5-10 are indicative of medium resistance and $<5$ are indicative of low resistance (Mazarri and Georghiou 1995).

Statistical Analyses: One-way Analysis of Variance (ANOVA) was used to determine the significant difference on the mortality and Resistance status of the larvae of Culex quinquefasciatus between the control and the experimental groups. P-value of less than 0.05 was significantly different. Probit analysis was also used to determine LC50 (lethal concentration to cause $50 \%$ mortality in the population) by plotting regression line. 


\section{RESULTS}

The results of the larvae of Culex quinquefasciatus exposed to methanol leaf extract of Calotropis procera are presented in Table 1. The percentage mortality of the larvae decreased steadily from the F0 generation $(56.20 \%)$ to the F10 generation $(9.40 \%)$. The lethal concentration that killed fifty per cent $\left(\mathrm{LC}_{50}\right)$ of the $\mathrm{F} 0$ population was $15.79 \mathrm{mg} / \mathrm{L}$. There was a gradual but steady increase of the $\mathrm{LC}_{50}$ values from $16.58 \mathrm{mg} / \mathrm{L}$ (F1 generation) to $32.98 \mathrm{mg} / \mathrm{L}$ (F10 generation). The percentage mortality and the LC50 across the 10 generations were inversely proportional. Resistance ratio values had a steady increase from the first filial generation (1.050 fold) to the tenth filial generation (2.089 fold).

Table 1: One-Way Analysis of Variance (ANOVA) on the resistance status of the larvae of C. quinquefasciatus from F1 generation to the F10 generation after exposure to 24 hours

\begin{tabular}{ccclcc}
\hline Generation & $\begin{array}{c}\text { Number of Larva } \\
\text { Exposed }\end{array}$ & \% Mortality & $\begin{array}{l}\text { Mean } \mathbf{(} \mathbf{+ S . ~ E )} \\
\text { Mortality }\end{array}$ & $\begin{array}{c}\text { LC50 } \\
\mathbf{m g} / \mathbf{L}\end{array}$ & $\begin{array}{c}\text { Resistance } \\
\text { Ratio (Fold) }\end{array}$ \\
F0 & 100 & 56.2 & $14.05 \pm 1.05$ & 15.79 & 1.050 \\
F1 & 100 & 52.0 & $13.05 \pm 1.01$ & 16.58 & 1.095 \\
\hline F2 & 100 & 48.2 & $12.05 \pm 0.94$ & 17.29 & 1.144 \\
F3 & 100 & 44.4 & $11.10 \pm 0.91$ & 18.95 & 1.200 \\
F4 & 100 & 40.6 & $10.15 \pm 0.87$ & 19.99 & 1.266 \\
F5 & 100 & 36.8 & $9.20 \pm 0.89$ & 20.65 & 1.308 \\
F6 & 100 & 32.2 & $8.05 \pm 0.89$ & 21.18 & 1.341 \\
F7 & 100 & 27.6 & $6.90 \pm 0.94$ & 22.80 & 1.444 \\
F8 & 100 & 21.0 & $5.25 \pm 0.83$ & 25.16 & 1.593 \\
F9 & 100 & 16.4 & $4.20 \pm 0.67$ & 32.98 & 2.089 \\
F10 & 100 & 9.4 & $2.35 \pm 0.80$ & & \\
\hline
\end{tabular}

Significant at $\mathrm{p} \leq 0.05$

\section{DISCUSSION}

Calotropis procera is a promising botanicals for use in the control of vector species. In our studies, we found the methanol leaf extract of this plant effective against the larvae of Culex quinquefasciatus. Other researchers (Singh et al., 2005; Elimam et al., 2009; Kumar et al., 2012; Anjum et al., 2016) reported similar effects of Calotropis procera against Culex quinquefasciatus and other mosquito species. Despite the efficacy of Calotropis procera on vector species, there seems to be paucity of information on the selection pressure of this plant on vector species. Thus, it is not known whether continual exposure of the extract of Calotropis procera on vector species will cause the development of resistance or not.

In this study, we found out that the extract of Calotropis procera caused slight decrease of mortality with subsequent exposures. According to the World Health Organization procedure for testing (WHO, 2016), if resistance ratio is less than 5 fold, the resistance is low; if it is between 5 and 10 fold, it is moderate; resistance ratio above 10 fold means that the resistance is high. Thus, exposure of Culex quinquefasciatus to the extract of Calotropis procera yielded low resistance of 2.089 fold. This makes it interesting because it is most likely going to address the issue of resistance which is prevalent in the use of synthetic insecticides (Hemingway and Ranson, 2004; Rivero et al., 2010; Chareonviriyaphap et al., 2013). Similar to this report is the use of Bacillus thuringiensis var. israelensis which yielded only 2.78 fold tolerance after 20 generations (Saleh et al., 2003).
On the other hand, selection with synthetic insecticides has always yielded resistance in multiple folds. For instance, ElSheik et al. (2014) selected the populations of Culex pipiens with lambda-cyhalothrin and malathion for 11 generations and recorded 57 and 305 fold resistance. Similarly, when the population Culex quinquefasciatus was selected with deltamethrin in India, there was approximately 298-fold resistance in the tenth generation (Sarkar et al., 2009). This rapid increase may be attributed to the fact that synthetic insecticides are reported to increase the levels of detoxifying enzymes, thus making them effective against the insecticides in question (Zibaee and Bandani, 2010).

\section{CONCLUSION}

In conclusion, methanol leaf extract of Calotropis procera shows toxic effect on the $C$. quinquefasciatus larvae resulting in high mortality recorded. The leaf of Calotropis procera could thus be added to the growing list of botanicals with antimosquito properties that could be harnessed for the control of mosquito species and replacement for synthetic pesticides. Slow resistance development on exposure to the extract of this plant is added advantage over synthetic insecticides.

\section{REFERENCES}

Andreadis, T. G., Armstrong, P. M. and Bajwa, W. I. (2010): Studies on hibernating populations of Culex pipiens from a West Nile virus endemic focus in New York City: Parity rates and 
isolation of West Nile virus Journal of the American Mosquito Control Association, 26:257-264.

Anjum, S.I., Hussain, S., Attaullah, M., Khan, H.U., Khattak, B. and Fouad, H. (2016). Evaluation of the larvicidal potential of Calotropis procera plant extract against Culex pipiens. International Journal of Mosquito Research, 3(6): 01-05

Brown, A.W. and Pal, R. (1971). Insecticide resistance in arthropods. Public Health Paper, 38:1 491.

Chareonviriyaphap, T., Bangs, M.J., Suwonkerd, W., Kongmee, M., Corbel, V., Ngoen-Klan, R., (2013). Review of insecticide resistance and behavioral avoidance of vectors of human diseases in Thailand. Parasites Vectors, 6: 280.

Choochote W, Tueton B, Kanjanapothi D, Rattanachanpichoi E, Chaithong U, Chainong P, Jitpakdi A, Tippawangkosol P, Rivong D, Pitasawat B (2004). Potential of crude seed extract of celery, Apium graveolus L., against the mosquito Aedes aegypti (L.) (Diptera: Culicidae). Journal of Vector Ecology, 29(2): 340-6.

David, M. R., Ribeiro, G. S. and de Freitas, R. M. (2012). Bionomics of Culex quinquefasciatus within urban areas of Rio de Janeiro, Southeastern Brazil.Revista Saúde Pública, 46(5): S0034-89102012000500013.

Diaz-Badillo, A., Bolling, B. G., Perez-Ramirez, G., Moore, C. G., Martinez-Munoz, J. P., Padilla-Viveros, A. A., CamachoNuez, M., Diaz-Perez, A., Beauty, B. J. and de Lourdes, M. M. (2011). The distribution of potential West Nile virus vectors, Culex pipiens and Culex pipiens quinquefasciatus (Diptera: Culicidae), in Mexico City. Parasites \& Vectors, 4:70.

Elimam, A.M., Elmalik, K.H. and Ali, F.S. (2009). Efficacy of leaves extract of Calotropis procera Ait. (Asclepiadaceae) in controlling Anopheles arabiensis and Culex quinquefasciatus mosquitoes. Saudi Journal of Biological Sciences, 16: 95- 100

El-sheik, E.A., Ashour, M.A., Aamir, M.M. and Gamal, M.M. (2014). Monitoring the effect of insecticide selection on Culex pipiens (Diptera: Culicidae) larval susceptibility to malathion and lambda-cyhalothrin. Journal of Entomology, 11(1): 14-24.

Finney, D.J. (1971). Probit Analysis. Cambridge: Cambridge University Press.

Govindarajan, A., Kelleher, R. J., Tonegawa, S. (2008). A clustered Plasticity Model of Long-term Memory Engrams. Nature Reviews Neuroscience, 7: 575-583.

Govindarajan, M. and Rajeswary, M. (2014). Mosquito larvicidal properties of Imatiens balsamania (Balsamaniaceae) against Anopheles stephensi Aedes aegypti and Culex quinquefasciatus (Diptera: Culicidae). Journal of Coastal Life medicine, 2(3): 222-224.

Hemingway, J. and Ranson, H. (2000). Insecticide resistance in insect vectors of human disease. Annual Review of Entomology. $45,371-391$.

Jitpakdi, A., Choochote, W., Panart, P., Tookyang, B., Panart, K., Prajakwong, S. (1998). Possible transmission of two types of Wuchereria bancrofti in Muang District, Chiang Mai, northern India.

Kumar, G., Karthik, L., Rao, K.V.B., Kirthi, A.V., JayaseelanC. and AbdulRahuman, A. (2012). Phytochemical composition, mosquito larvicidal, ovicidal and repellent activity of Calotropis procera against Culex tritaeniorhynchus and Culex gelidus. Bangladesh Journal of Pharmacology, 7: 63-69.

Malcolm, C. A. (1988) Current status of pyrethroids resistance in (Diptera: Culicidae). Parasitology Today, 4: S13-S15.

Mazarri, M. B. and Georghiou, G. P. (1995) Characterization of resistance to organophosphate, carbamate, and pyrethroid insecticides in field populations of (Aedes aegypti). Journal of the American Mosquito Control Association, 11(3): 315-22.

Morin, C. W. and Comrie, A. C. (2010). Modeled response of the West Nile virus vector Culex quinquefasciatus to changing climate using the dynamic mosquito simulation model. International Journal of Biometeorology, 54(5):517-29.

Paeporn, P., Ya-umphan, P., Supaphathom, K., Savanpanyalert, P., Wattanachai, P. and Patimaprakorn, R. (2004). Insecticide Susceptibility and Selection for Resistance in a Population of Aedes Aegypti From Ratchaburi Province, Thailand. Tropical Biomedicine, 21(2): 1-6

Patel, H. V., Patel, J. D. and Patel, B. (2014), Comparative efficacy of phytochemical analysis and antioxidant activity of methanolic extract of Calotropis gigantea and Calotropis procera. International Journal of Life Science Biotechnology Pharmacology Research, 5(2):107-13.

Pumidonming, W., Polseela, P., Maleewong, W., Pipitgool, V., Poodendaen, C. (2005). Culex quinquefasciatus in Phitsanulok as a possible vector of nocturnally periodic Wuchereria bancrofti transmission in Myanmar immigrants. Southeast Asian Journal of Tropical Medicine and Public Health 36 (Suppl. 4), 176-179.

Raymond, M. (1985) Log - probit analysis basic programme of microcomputer. Cohiers ORTOM Series. Entomology Medicale et parasitology, 23;117-121. 
Rios-Ibarra, C., Blitvich. B., Farfan-Ale, J., Ramos-Jimenez, J., Muro-Escobedo, S., Martínez Rodriguez, H., OrtizLópez, R., Torres-López, E. and Rivas-Estilla, A. (2010): Fatal human case of West Nile disease, Mexico, 2009.Emerging Infectious Diseases, 16:741-742.

Rivero, A., Vezilier, J., Weill, M., Read, A.F., Gandon, S. (2010). Insecticide control of vector- borne diseases: when is insecticide resistance a problem? Plos Pathogens, 6(8):

Saleh, M.S., El-Meniawi, F.A., Kelada, N.L. and Zahran, H.M. (2003). Resistance development in mosquito larvae Culex pipiens to the bacterial agent Bacillus thuringiensis var. israelensis. Journal of Applied Entomology, 127(1): 29-32

Sarkar, M., Bhattacharyya, I.K., Borkotoki, A., Baruah, I. and Srivastava, R.B. (2009). Development of physiological resistance and its stage specificity in Culex quinquefasciatus after selection with deltamethrin in Assam, India. Memórias do Instituto Oswaldo Cruz, 104(5): 673-677.

Sarwar, M., Ahmad, N. and Toufiq, M. (2009). Host plant resistance relationshiphs in chickpea (Cicer arietinum Linn.) against gram pod borer (Helicoverpa armigera Hubner). Pakistan Journal of Botany, 41(6): 3047-3052.

Shaalan, E. A. S., Canyon, D., Younesc, M. W. F., AbdelWahab, H. and Mansoura, A. H. A. (2005). Review of botanical phytochemicals with mosquitocidal potential. Environment International, 31: 1149-66.

Shahia, M., Hanafi-Bojdb, A. A., Iranshahic, M., Vatandoostb, H. and Hanafi-Bojdd, M. Y. (2010). Larvicidal efficacy of latex and extract of Calotropis procera (Gentianales: Asclepiadaceae) against Culex quinquefasciatus and Anopheles stephensi (Diptera: Culicidae). Journal of Vector Borne Diseases; 47:185-8.

Singh, R.K. Mittal, P.K. and Dhiman, R.C. (2005). Laboratory study on larvicidal properties of leaf extract of Calotropis procera (Family-Asclepiadaceae) against mosquito larvae. Journal of Communicable Diseases, 37 (2): 109.113
Triteeraprapab, S., Kanjanopas, K., Suwannadabba, S., Sangprakarn, S., Poovorawan,Y., Scott, A.L. (2000). Transmission of the nocturnal periodic strain of Wuchereria bancrofti by Culex quinquefasciatus: establishing the potential for urban filariasis in Thailand. Epidemiology and Infection, 125, 207-212.

Verma DR, Kakkar A, Bais N, Dubey P. (2011) Antifungal Activity of Calotropis Procera Journal of Global Pharmacy Technology;3(9):11-4.

WHO (1992). Vector resistance to pesticides. $15^{\text {th }}$ report of the expert committee on vector biology and control. Technical Report Series. p.818.

WHO (2005). Guidelines for Laboratory and Field Testing of Mosquito Larvicides. WHO communicable disease control, prevention and eradication. WHO pesticide evaluation scheme. WHO/CDS/WHOPES/GCDPP/2005.13.

WHO (2016). Monitoring and managing insecticide resistance in Aedes mosquito populations.

World Health Organization (1995). Vector Control for Malaria and other mosquito borne diseases. WHO Technical Report 857, World Health Organization, Geneva Switzerland.

World Health Organization (2002). WHO Traditional medicine strategy 2002-2005. Geneva. 2002. WHO/EDM/TRM/2002.1.

Zibaee, A., and Bandani, A. R. (2010). Effects of Artemisia annua L. (Asteracea) on digestive enzymes profiles and cellular immune reactions of sunnpest, Eurygaster integriceps Heteroptera: Scutellaridae), against Beauvaria bassiana. Bulletin of Entomological Research, 100: 185-196. 